\title{
Impaired VEGF Signaling in Lungs with Hypoplastic Esophageal Atresia and Effects on Branching Morphogenesis
}

\author{
Xiaomei Liua Caixia Liu Tie Ma $^{b}$ Yisheng Jiao ${ }^{a}$ Jianing Miaoc Linlin Gaoc \\ aDepartment of Obstetrics and Gynecology, Shengjing Hospital of China Medical University, Shenyang, \\ ${ }^{b}$ Department of Pathology, Shengjing Hospital of China Medical University, Shenyang, 'Central \\ laboratory, Shengjing Hospital of China Medical University, Shenyang, P. R. China
}

\section{Key Words}

VEGF • Flt-1 • Esophageal atresia $・$ Fetal lung development $\bullet$ Branching

\begin{abstract}
Background/Aims: Patients with esophageal atresia (EA) and tracheoesophageal fistula (TEF) often suffer chronic respiratory tract disease. We previously reported that primary lung maldevelopment caused by deficient branching of embryonal airways in experimental EA-TEF was induced by Adriamycin. In this study, we investigated the Vascular endothelial growth factor (VEGF) pathway in the developing lung in an EA-TEF rat model. We further analyzed the effect of recombinant VEGF treatment in vitro on branching morphogenesis of embryo lungs in experimental EA-TEF. Methods: Pregnant rats received either Adriamycin or vehicle on E7, E8 and E9. Lungs were recovered at E15, E18 and E21. Expression of VEGF and receptors (Flk-1 and Flt-1) were assessed by quantitative PCR, immunohistochemistry and immunoblotting. E13 lungs were cultured for 72 hours with $50 \mathrm{ng} / \mathrm{mL}$ of recombinant rat VEGF in serum-free medium. The rates of increase in bud count and airway contour were evaluated. Results: Our results showed a significant downregulation of VEGF during pseudoglandular and canalicular stages. In contrast, there were significantly higher levels of the Flt-1 receptor in the canalicular stage, which may represent a compensatory response to decreased VEGF. However, both variables returned to normal levels at the saccular stage. Exogenous VEGF treatment enhanced hypoplastic lung growth, evidenced by the increase in bud count and airway contour. Conclusions: A VEGF signaling defect possibly plays an important role in defective embryonic airway branching. Additionally, VEGF treatment may accelerate lung growth in EA-TEF lungs.

\section{Introduction}

Esophageal atresia (EA) is the most frequent anomaly of the esophagus and is characterized by complete discontinuity of the esophagus with or without an abnormal connection between the trachea and the distal esophagus (tracheo-esophageal fistula,


TEF). EA affects about 1 in every 4099 births worldwide [1]. With current survival rates approaching 90\% [2], long-term sequelae have become the focus of attention.

Persistent respiratory symptoms are commonly observed in children with EA, including bronchitis, brassy cough, chronic cough, pneumonia and wheezing [3-8]. Experimental models and human findings have demonstrated that developmental abnormalities of tracheal structure and innervation or lung hypoplasia might account for these sequelae beyond childhood [9-12]. In agreement with other reports, we previously reported that the lungs were hypoplastic in rats with experimental EA-TEF due to defective embryonal airway branching. These findings prompted us to unravel the mechanisms underlying the defective lung development in EA-TEF patients.

Vascular endothelial growth factor (VEGF, also designated VEGF-A), a potent mitogen and angiogenic factor, is considered to play multiple crucial roles in lung development. It exerts its functions through two high-affinity tyrosine kinase receptors, designated VEGF receptor 1 (VEGFR-1; alias FLT-1) and VEGFR-2 (alias KDR/ FLK-1). Various studies have suggested that the VEGF pathway is critical for normal lung development. Studies by Del Moral et al. point out that VEGF signaling plays a key functional role in early embryonic lung epithelial and endothelial crosstalk and branching morphogenesis [13]. Disruption of

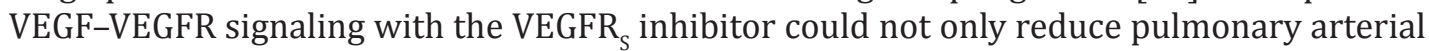
density but also lead to reduced alveolarization and immature lung formation. These results suggest that impaired VEGF signaling impacts vascular development as well as abnormal airway growth [14-16]. The importance of VEGF for normal lung development is also highlighted by the fact that VEGF levels in tracheal fluid and lung tissue from infants dying from bronchopulmonary dysplasia are markedly reduced [17].

These facts led us to speculate that disruption of VEGF-receptor signaling might contribute to defective branching morphogenesis in EA-TEF. The objective of this study was to determine the expression of VEGF and its receptors in the developing lung using a rat model of EA-TEF induced by Adriamycin and to analyze the effect of exogenous VEGF on branching morphogenesis and epithelial differentiation of embryo lungs.

\section{Materials and Methods}

\section{Animals}

All procedures/protocols were approved by the Animal Research Committee of China Medical University (Shenyang,China). Timed-pregnant Wistar rats received three intraperitoneal injections on embryonic days E7, E8 and E9, each with $1.75 \mathrm{mg} / \mathrm{kg}$ Adriamycin (ADR, Haizheng Pharmaceutical Co. Ltd, Taizhou, China) in saline, as described previously [18]. This induces EA-TEF in 79.4\% of fetuses [18]. Control rats received an equivalent volume of saline. A subset of rat dams were killed by injection of potassium chloride on E15, E18 and E20. Embryo lungs were removed and dissected free from the trachea. Another subset of dams were killed on E13 and fetal lung rudiments were collected aseptically for explant studies as described below. The lungs of ADR-treated animals were collected irrespective of the presence or absence of EA/TEF since they share similar weight, histology and branching mode of explants, as evidenced by our previous research. The experimental design is summarized in Fig. 1.

\section{Morphometry}

Immunohistochemical (IHC) studies were performed on fixed lungs. As described previously [18], after tracheal cannulation, $4 \%$ paraformaldehyde was injected at $<10 \mathrm{~cm} / \mathrm{H}_{2} \mathrm{O}$ for alveolar distention and fetal lungs were harvested, fixed and embedded in paraffin. IHC staining was performed on $4 \mu \mathrm{M}$ sections using standard techniques with anti-VEGF (19003-1-AP, Proteintech, Rosemont, Illinois, USA) and anti-Flt-1 (ab32152, Abcam, Cambridge, Massachusetts, USA) antibodies.

RNA extraction and RT-PCR

Total RNA was isolated from snap-frozen lungs with TRIzol reagent (Invitrogen, Carlsbad, California, USA) according to the manufacturer's protocol. RNA concentration was determined in duplicate using a 
Fig. 1. Diagram of experimental design. Timed-pregnant Wistar rats received three intraperitoneal injections of $1.75 \mathrm{mg} / \mathrm{kg}$ Adriamycin or saline on E7-E9. A subset of rat dams were sacrificed on E13 and embryo lung rudiments were collected and cultured in DMEM/F12 medium with or without recombinant VEGF164 for 72 hours. Another subset of dams were sacrificed on E15, E18 and E20 and fetal lungs were collected for IHC, western blot and quantitative PCR studies.

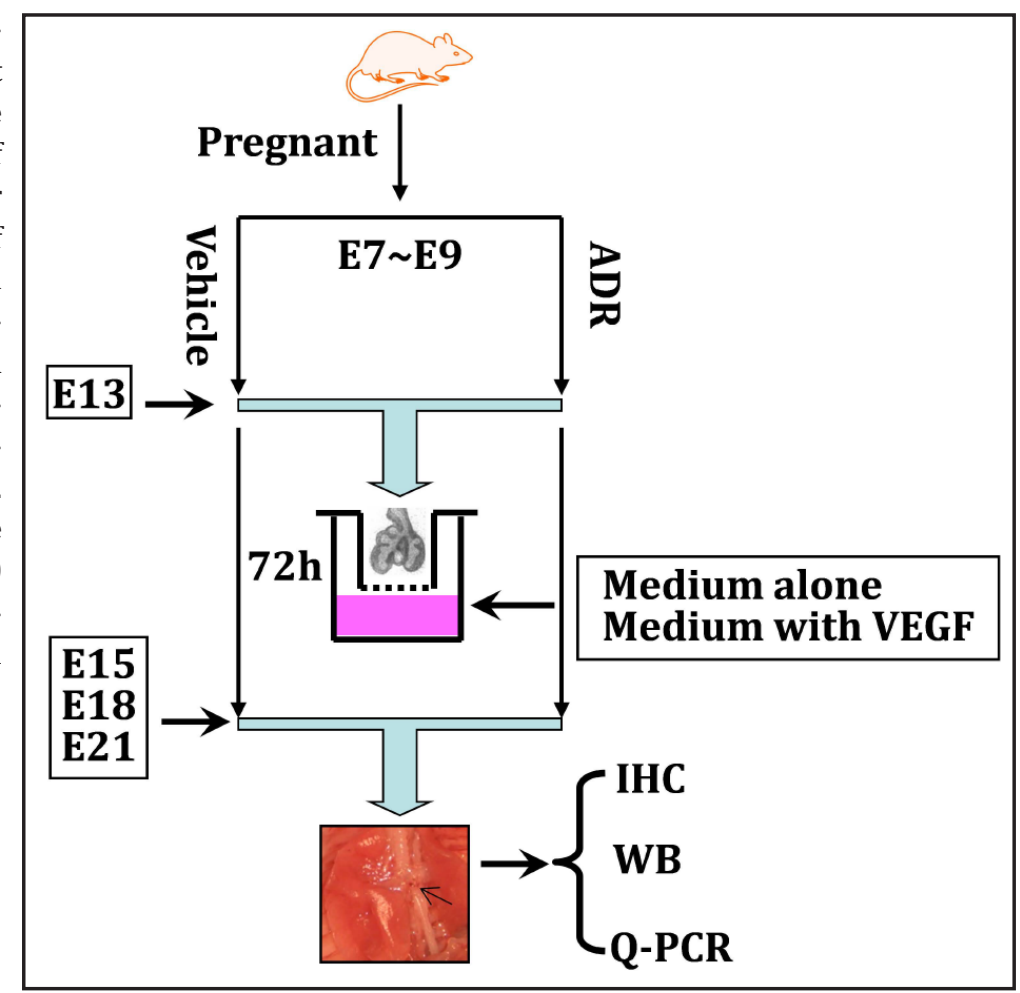

Table 1. Primers for quantitative PCR. $\beta$-actin was used as a housekeeping gene for normalization of data

\begin{tabular}{lllc}
\hline Gene name & $\begin{array}{l}\text { Accession } \\
\text { Number }\end{array}$ & Primer Sequences & Size( bp) \\
\hline Vegf & AF215726 & $\begin{array}{l}\text { F: 5- CAGCTATTGCCGTCCAATTGA -3 } \\
\text { R: 5- CCAGGGCTTCATCATTGCA-3 }\end{array}$ & 131 \\
Flt-1 & NM_019306 & $\begin{array}{l}\text { F: 5- TGTCCTCAACTGCACCGTCAC-3 } \\
\text { R: 5- CCGCTGCCTGATAGATGCTCTC-3 }\end{array}$ & 100 \\
Flk-1 & NM_013062 & $\begin{array}{l}\text { F: 5- TAGCACGACAGAGACTGTGAGGT-3 } \\
\text { R: 5- TGAGGTGAGAGAGATGGGTAGG-3 }\end{array}$ & \\
$\beta$-Actin & NM_031144.3 & $\begin{array}{l}\text { F: GGAGATTACTGCCCTGGCTCCTA } \\
\text { R: GACTCATCGTACTCCTGCTTGCTG }\end{array}$ & \multirow{2}{*}{190} \\
\hline
\end{tabular}

spectrophotometer (Nano Vue; GE Healthcare, Buckinghamshire, England, UK). Two micrograms of total RNA was reverse transcribed using the M-MLV First Strand kit (C28025-032, Invitrogen). To minimize variation in the reverse transcription reaction, all RNA samples from a single experimental setup were reverse transcribed simultaneously. RT-PCR was performed on a LightCycle480 instrument (Roche, Basel, Switzerland). Quantitative PCR was used for the analysis of VEGF, Flt-1 and Flk-1 mRNA levels in the fetal lung. cDNA was amplified using a LightCycler ${ }^{\circledR} 480$ SYBR Green I Master instrument (Roche, Mannheim, Germany) in a $20 \mu \mathrm{l}$ reaction solution with specific primers for pan-VEGF, Flt-1 and Flk-1 (Table 1). Specificity of PCR products were confirmed by analysis of the dissociation curve. In addition, the expected amplicon size and the absence of nonspecific products were confirmed by analysis of the PCR products on $2 \%$ agarose gels, subsequently stained with ethidium bromide and visualized under UV light. The relative mRNA levels were calculated using the $2^{-\Delta \Delta \mathrm{Ct}}$ method after normalization with the housekeeping gene $\beta$-actin.

Protein assay and Immunoblotting

Immunoblotting was used to detect the presence of VEGF and Flt-1 protein in rat embryo lungs at each time point. Frozen lungs were washed with ice-cold PBS and homogenized in RIPA lysis buffer (50 


\section{Cellular Physiology Cell Physiol Biochem 2016;39:385-394 \\ \begin{tabular}{l|l|l} 
and BOI: 10.1159/000445632 & $\begin{array}{l}\text { C } 2016 \text { The Author(s). Published by S. Karger AG, Basel } \\
\text { www.karger.com/cpb }\end{array}$
\end{tabular}}

Liu et al.: VEGF Signaling in Esophageal Atresia Lungs

mM Tris- $\mathrm{HCl}$, pH 7.4, $150 \mathrm{mM} \mathrm{NaCl}, 5 \mathrm{mM}$ EDTA, $5 \mathrm{mM}$ EGTA, $1 \%$ sodium deoxycholate, $1 \mathrm{mM}$ PMSF, $0.1 \%$ SDS, $1 \%$ Triton X-100, $50 \mathrm{mM} \mathrm{NaF}, 0.5 \mathrm{mM} \mathrm{Na}_{3} \mathrm{VO}_{4}$ ). Lysates were centrifuged at $12,000 \times g$ for 20 minutes at $4{ }^{\circ} \mathrm{C}$ and supernatants collected. Total protein content was determined using the Bradford protein assay (Bio-Rad Laboratories, Hercules, CA, USA). Equal amounts of protein were separated by sodium dodecyl sulfate (SDS)-polyacrylamide gel electrophoresis and transferred onto a polyvinylidene difluoride (PVDF) membrane (Millipore, Billerica,Massachusetts, USA), as described by Towbin et al. [19]. The PVDF membrane was blocked with $5 \%$ nonfat milk and immunoprobed with anti-VEGF and anti-Flt- 1 antibody at $4^{\circ} \mathrm{C}$ overnight, followed by horseradish peroxidase (HRP)-conjugated secondary antibody for 2 hours at room temperature. Visualization of antigen-antibody complexes were accomplished using ECL plus reagent (GE Healthcare, Piscataway, NJ, USA). Quantity One software (Bio-Rad) was used to analyze optical density (OD) of protein bands. Relative expression quantity of target protein was illustrated as the percentage of the OD of target protein adjusted with corresponding $\beta$-actin OD. Experiments were performed at least three times for each antibody.

\section{In vitro lung explant studies}

On the $13^{\text {th }}$ day of gestation, embryos were aseptically removed by cesarean section from pregnant rats under chloral hydrate anesthesia. As previously reported [18], fetal lung rudiments were collected aseptically, transferred to Costar-Transwell cells (Corning, Corning, NY, USA) and cultured at the air-liquid interface in serum-free DMEM/F12 medium (Gibco, Invitrogen, Carlsbad, CA, USA) supplemented with 100 $\mathrm{U} / \mathrm{ml}$ penicillin and $100 \mu \mathrm{g} / \mathrm{ml}$ streptomycin. The explants were placed in humidified incubators at $37^{\circ} \mathrm{C}$ with an atmosphere of air plus 5\% $\mathrm{CO}_{2}$ and cultured for 72 hours. For analysis of VEGF effects, lung explants were treated daily with recombinant rat VEGF (Gibco, Invitrogen) at $50 \mathrm{ng} / \mathrm{ml}$ final concentrations from time 0 to 72 hours. The lung cultures were divided into 3 groups $(n=8)$ : Group I, controls; Group II, ADR without VEGF; Group III, ADR with VEGF. The explant lungs were photographed daily on an inverted phasecontrast microscope and the digitized lung images were blindly analyzed for lung bud count and airway contour using Image Pro-Plus software (Media Cybernetics, Washington, DC, USA). The following formula was used to calculate an increase in lung bud count rate: Increased rate $=($ Bud count at each time point - bud count at time zero) / bud count at time zero, the increase in airway contour were calculated in the same way.

\section{Statistical analysis}

Data are presented as the mean \pm SEM. Statistical analyses were performed with GraphPad Prism 5 (GraphPad software Inc, San Diego, CA, USA). Between-group differences were tested with nonparametric methods (Mann-Whitney test for two groups and KruskallWallis test for more than two groups). When appropriate, parametric methods (ANOVA or Student's t test) were preferred. A statistical probability of $P<0.05$ was considered significant.

\section{Results}

VEGF expression in the developing lung

By IHC, VEGF protein was mainly localized to the bronchial epithelial cells and type 2 pneumocytes. Positive VEGF staining was also noted in the mesenchyme. No difference was observed in the localization pattern of VEGF in normal and hypoplastic lungs at all three developmental stages (Fig. 2). We did not calculate the grey value because evaluation of staining intensity by IHC is subject to observer variability.

We proceeded to assess the expression of VEGF and receptors by quantitative PCR and/or western blot, as the latter two methods are more quantifiable and reproducible. The results of quantitative PCR experiments indicated that both groups shared similar developmental expression patterns of pan-VEGF mRNA. From E15 to E18, pan-VEGF mRNA levels continued to increase, but at E15 and E18 there was a tendency toward lower levels in hypoplastic lungs compared to control lungs. Although, at E18, the change did not achieve statistical significance. For parallel protein level analyses, we also used $\beta$-actin as the loading control. Similar to our mRNA data, we observed decreases in VEGF protein levels in 
Fig. 2. Effect of ADR on VEGF expression in fetal lungs. (A, B) Pan-VEGF mRNA levels in the fetal lungs of both groups were determined by quantitative PCR and specificity of PCR products were confirmed by visualization on $2 \%$ agarose gels. Data are expressed relative to the control at E15, after normalization with $\beta$-actin mRNA levels. Results are presented as the mean \pm SEM. ${ }^{*} P$ $<0.05$, ADR-treated vs. control at the same time point, inter-group; ${ }^{\#} P<0.05$, E18 or E21 vs. E15, inner-group. (C-F) Representative photomicrographs of IHC staining for VEGF in the lung sections from controls (C, E) and ADR-treated rats (D, F) on E18 (upper panel) and E21 (lower panel) (Original magnification $400 \times$, scale bar $=100$ $\mu \mathrm{m})$. VEGF was mainly expressed in the airway epithelium and also detectable in some mesenchymal cells (black arrowhead). (G, H) Representative immunob-

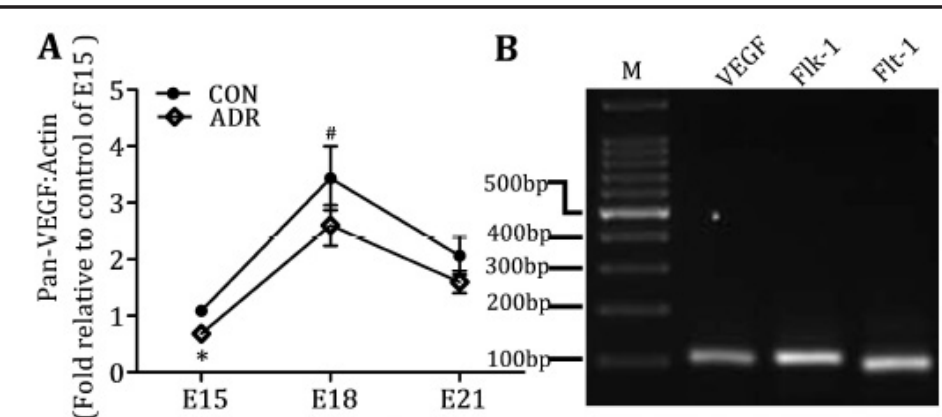

\section{C} $\begin{array}{llll}\text { C } & \text { E15 } & \text { E18 } & \text { E21 }\end{array}$

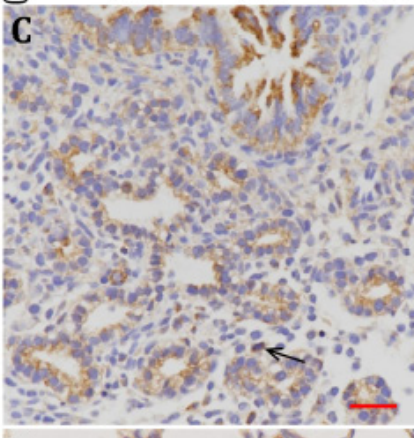

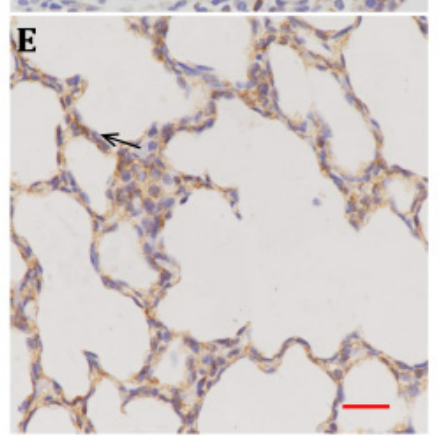

G

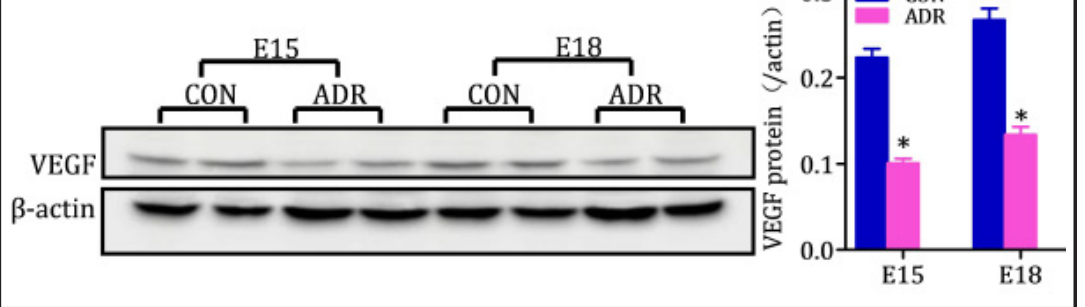

lots and densitometric analysis of VEGF protein in the fetal lungs at E15 and E18. Results were normalized relative to the expression of $\beta$-actin. ${ }^{*} P<0.05$ vs. control at the same time point.

hypoplastic lungs at E15 and E18 compared to controls, whereas protein levels restored to normal at E21.

VEGF receptors in the developing lung

Positive immunoreactivity for Flt-1 was found in mesenchymal cells, in vascular structures of the mesenchyme as well as in the luminal airway epithelium. In ADR-treated lungs, Flt-1 mRNA showed a similar expression trend to that of normal lungs of equivalent stage. However, Flt-1 mRNA was significantly increased in hypoplastic lungs compared with control lungs at E18 $(P<0.05$; Fig. 3). Similar to our mRNA data, we observed increased Flt protein levels assayed by western blot. In contrast, ADR did not induce an alteration in

\section{KARGER}


Fig. 3. Temporal expression of VEGF receptors in the ADR treated lung. Flt-1 (A) and Flk-1 (B) mRNA levels in developing lungs were determined by quantitativePCR and results are expressed relative to the control at E15. Data are presented as the mean \pm SEM. ${ }^{*} P<0.05$, ADR-treated vs. control at the same time point, inter-group; $\quad$ " $P$ $<0.05$, E18 or E21 vs. E15, inner-group. (C-F) Immunostaining for Flt-1 protein in embryo lung sections from controls (C, E) and ADR-treated rats $(D, F)$ at E18 (upper panel) and E21 (lower panel). Flt-1 was widespread in the mesenchyme andluminal airway epithelium (black arrowhead) (Original magnification $400 \times$, scale
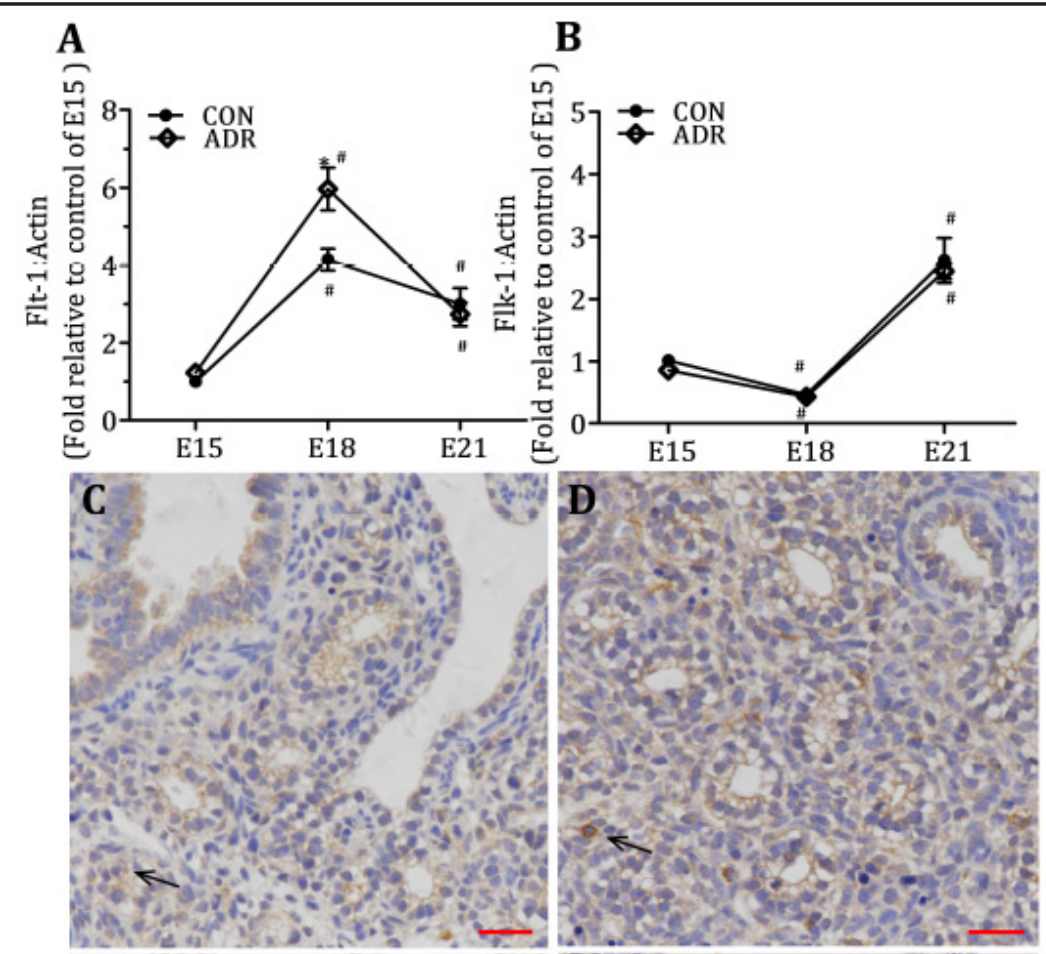
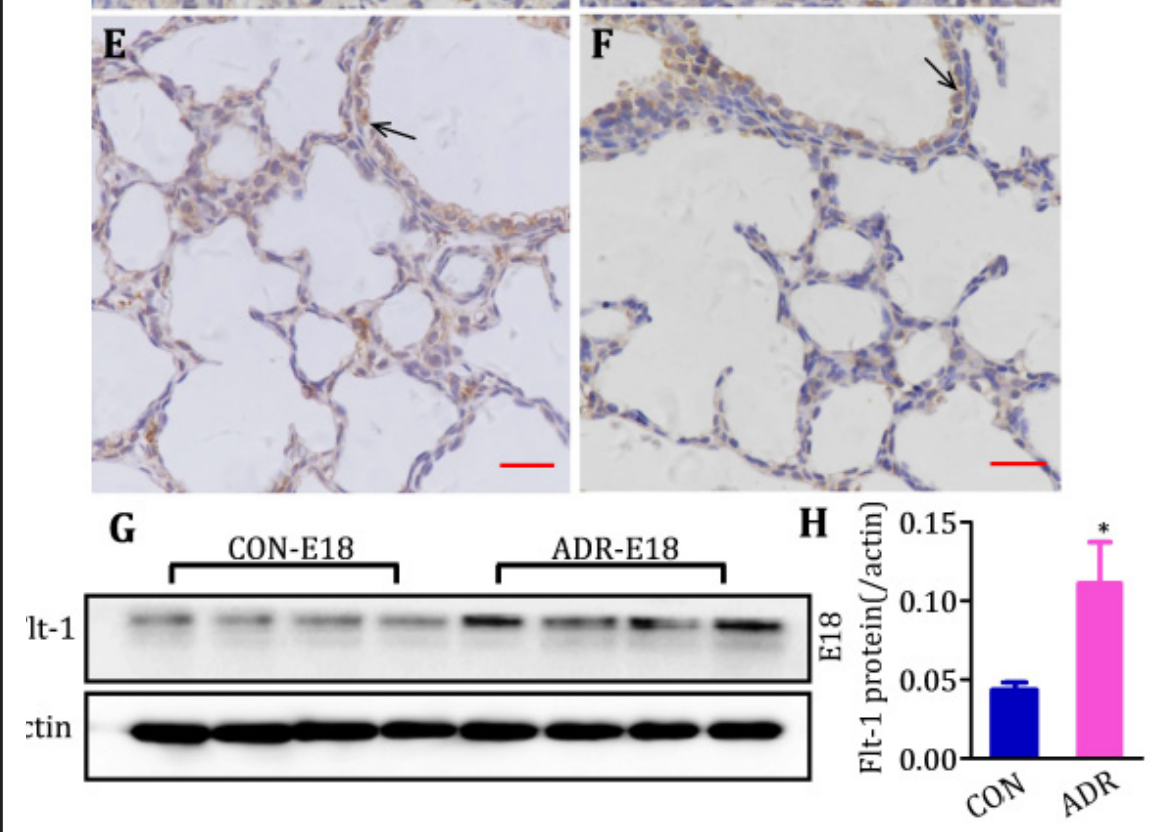

bar $=100 \mu \mathrm{m}) .(\mathrm{G}, \mathrm{H})$ Representative immunoblots and densitometric analysis of Flt-1 protein expression in the fetal lungs at E18. Results were normalized relative to the expression of $\beta$-actin. ${ }^{*} P<0.05$, vs. control at the same time point.

Flk-1 mRNA levels. Both groups shared a similar trend; slightly declining levels at E18 and reaching highest levels at E21.

Effect of VEGF on branching morphogenesis in lung explants

In order to unravel the potential role of VEGF in EA lung development, functional studies were performed using lung explant cultures. ADR EA and ADR-no EA lungs were not divided 


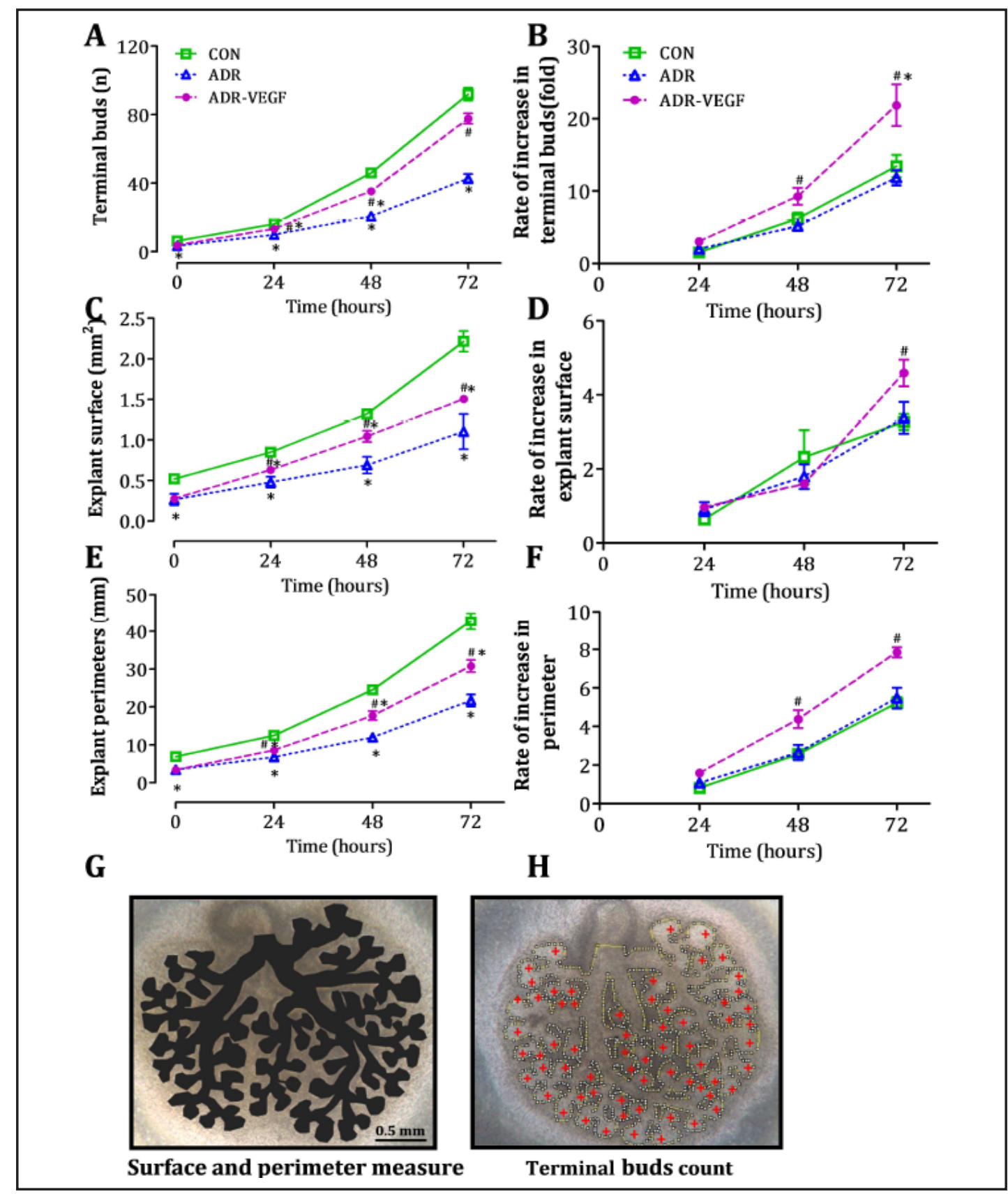

Fig. 4. Effect of VEGF treatment on branching morphogenesis of fetal lung explants. E13 lungs were treated with VEGF164 (50 ng/ml) for 72 hours. Terminal buds counts (A, B), explant surface (C, D) and perimeter (E, F) were significantly reduced in the ADR-treated group compared with controls at all time points. Compared with the untreated lung, VEGF treatment markedly increased airway branching morphogenesis and terminal bud count. $(G, H)$ Representative photographs illustrate the marking of the airways for measurement of airway contour and terminal bud count. Results are presented as the mean \pm SEM. ${ }^{*} P<0.05$, vs. control at the same time point; ${ }^{\#} P<0.05$, ADR-VEGF vs. ADR at the same time point.

due to their similar weight, histology and branching mode of explant [18]. As we previously reported, ADR exposure led to deficient airway branching evidenced by a marked decrease in terminal bud count at all time points, though they shared the similar increase rate as controls (Fig. 4). However, with VEGF treatment, the terminal bud count in hypoplastic lungs 
Liu et al.: VEGF Signaling in Esophageal Atresia Lungs

was increased in a remarkably accelerated fashion and restored to normal levels after 48 hours of culture. The same accelerated pattern was also seen in airway contour. However this increasing trend was less remarkable, so the surface and perimeter of the explants in the ADR-VEGF group were always smaller than those of the control explants at the same time point.

\section{Discussion}

Survivors of EA-TEF often suffer from chronic respiratory tract disease characterized by hoarse cough, repeated pneumonia or bronchiectasis and chronic bronchitis [20-22]. Peptic bronchitis, gastro-esophageal reflux or fistula stump account in part for these sequelae, but defects in the airway or lung parenchyme, or lung hypoplasia might also play a role [12, $23,24]$. We previously reported deficient embryonal lung branching and lung hypoplasia in fetal rats with EA-TEF [18]. Although several pathways (e.g. Shh, FGF10) are reported to have been altered in the lungs of fetal rats with EA-TEF $[25,26]$, the precise mechanisms of impaired airway branching are still unclear.

Rat lung development is divided into five distinct stages: embryonic, pseudoglandular, canalicular, saccular and alveolar [27]. The genetic program of fetal lung development is tightly regulated and complex, and can be influenced by epigenetic and environmental factors during the period of development. Several crucial players of normal lung morphogenesis have been already identified, mostly belonging to the hedgehog, wingless, transforming growth factor- $\beta$, fibroblast growth factor and VEGF signaling pathways [28-31].

VEGF belongs to the platelet-derived growth factor family. As a potent angiogenic factor and mitogenic growth factor, it has been shown to play multiple critical roles in pre- and postnatal lung development [32]. Temporo-spatial alteration of VEGF expression can yield a broad spectrum of effects on lung branching [33]. Targeted deletion of VEGF-A, Flk-1, or Flt-1 further demonstrated the importance of these signaling pathways in lung development [34-36].

In this study, we investigated VEGF and its receptors in the developing lung of experimental EA-TEF rats induced by Adriamycin, and evaluated the morphologic effect on hypoplastic lungs following VEGF treatment. Our results demonstrated a significant downregulation of VEGF during pseudoglandular and canalicular stages, which is consistent with the underdevelopment of EA lungs. In the canalicular stage, there was a significantly higher level of the receptor Flt-1, which may represent at least part of the compensatory response for decreased VEGF in an effort to restore normal growth. However, both of these variables returned to normal at the saccular stage (E21), whereas lung weight and branching still decreased in comparison with controls. These results indicate that deficient lung branching is not exclusively due to a disturbed VEGF pathway.

Earlier studies indicated that exogenous VEGF stimulates the growth and differentiation of lung epithelial cells and surfactant production in fetal lung explants of humans and rats $[37,38]$. More recently, evidence for the stimulatory effects of VEGF administration on structural maturation of the lung in both the normally grown and placentally restricted fetus has been described. [39]. However, to date, little is known about how exogenous VEGF affects branching morphogenesis of embryonal lungs in the EA model. Through in vitro experiments, the present study is the first to show that exogenous VEGF treatment enhanced hypoplastic lung growth, as evidenced by the increase in bud count and airway contour. This is in accordance with previous reports on the branching effect of exogenous VEGF on nitrofen-exposed lungs [40].

In summary, our findings suggest that disrupted molecular signaling in lung morphogenesis involving VEGF may result in impaired airway branching with consequent hypoplastic lungs. Furthermore, treatment with exogenous VEGF further enhanced branching and distal structural complexity of lung explants after maternal Adriamycin exposure. However, the mechanism of branching acceleration and cell differentiation by 


\begin{tabular}{|c|c|c|}
\hline Cellular Physiology & Cell Physiol Biochem 2016 & 39:385-394 \\
\hline and Biochemistry & $\begin{array}{l}\text { DOI: } 10.1159 / 000445632 \\
\text { Published online: July 04, } 2016\end{array}$ & $\begin{array}{l}\text { O } 2016 \text { The Author(s). Published by S. Karger AG, Basel } \\
\text { www.karger.com/cpb }\end{array}$ \\
\hline
\end{tabular}

VEGF remains unclear. These findings invite us to explore whether recombinant VEGF may provide an effective strategy to correct defective lung development in EA-TEF patients.

\section{Acknowledgements}

This work was supported in part by a grant from the National Natural Science Foundation of China (Grant No: 81370716, 81571449).

\section{Disclosure Statement}

The authors declare that they have no competing interests.

\section{References}

1 Nassar N, Leoncini E, Amar E, Arteaga-Vazquez J, Bakker MK, Bower C, Canfield MA, Castilla EE, Cocchi G, Correa A, Csaky-Szunyogh M, Feldkamp ML, Khoshnood B, Landau D, Lelong N, Lopez-Camelo JS, Lowry RB, McDonnell R, Merlob P, Metneki J, Morgan M, Mutchinick OM, Palmer MN, Rissmann A, Siffel C, Sipek A, Szabova E, Tucker D, Mastroiacovo P: Prevalence of esophageal atresia among 18 international birth defects surveillance programs. Birth Defects Res A Clin Mol Teratol 2012;94:893-899.

2 Spitz L: Oesophageal atresia. Orphanet J Rare Dis 2007;2:24.

3 Chetcuti P, Phelan PD: Respiratory morbidity after repair of oesophageal atresia and tracheo-oesophageal fistula. Arch Dis Child 1993;68:167-170.

4 Malmstrom K, Lohi J, Lindahl H, Pelkonen A, Kajosaari M, Sarna S, Malmberg LP, Makela MJ: Longitudinal follow-up of bronchial inflammation, respiratory symptoms, and pulmonary function in adolescents after repair of esophageal atresia with tracheoesophageal fistula. J Pediatr 2008;153:396-401.

5 Rintala RJ, Sistonen S, Pakarinen MP: Outcome of esophageal atresia beyond childhood. Semin Pediatr Surg 2009;18:50-56.

6 Sistonen S, Malmberg P, Malmstrom K, Haahtela T, Sarna S, Rintala RJ, Pakarinen MP: Repaired oesophageal atresia: Respiratory morbidity and pulmonary function in adults. Eur Respir J 2010;36:1106-1112.

7 Delacourt C, de Blic J: Pulmonary outcome of esophageal atresia. J Pediatr Gastroenterol Nutr 2011;52:S3132.

8 Landgraf MA, Silva RF, Correa-Costa M, Hiyane MI, Carvalho MH, Landgraf RG, Camara NO: Leptin downregulates lps-induced lung injury: Role of corticosterone and insulin. Cell Physiol Biochem 2014;33:835-846.

9 Xia H, Otten C, Migliazza L, Diez-Pardo JA, Tovar JA: Tracheobronchial malformations in experimental esophageal atresia. J Pediatr Surg 1999;34:536-539.

10 Usui N, Kamata S, Ishikawa S, Sawai T, Okuyama H, Imura K, Okada A: Anomalies of the tracheobronchial tree in patients with esophageal atresia. J Pediatr Surg 1996;31:258-262.

11 Briganti V, Oriolo L, Buffa V, Garofalo S, Cavallaro S, Calisti A: Tracheomalacia in oesophageal atresia: Morphological considerations by endoscopic and ct study. Eur J Cardiothorac Surg 2005;28:11-15.

12 van Dooren M, Tibboel D, Torfs C: The co-occurrence of congenital diaphragmatic hernia, esophageal atresia/tracheoesophageal fistula, and lung hypoplasia. Birth Defects Res A Clin Mol Teratol 2005;73:5357.

13 Del Moral PM, Sala FG, Tefft D, Shi W, Keshet E, Bellusci S, Warburton D: Vegf-a signaling through flk-1 is a critical facilitator of early embryonic lung epithelial to endothelial crosstalk and branching morphogenesis. Dev Biol 2006;290:177-188.

14 Gerber HP, Hillan KJ, Ryan AM, Kowalski J, Keller GA, Rangell L, Wright BD, Radtke F, Aguet M, Ferrara N: Vegf is required for growth and survival in neonatal mice. Development 1999;126:1149-1159.

15 Jakkula M, Le Cras TD, Gebb S, Hirth KP, Tuder RM, Voelkel NF, Abman SH: Inhibition of angiogenesis decreases alveolarization in the developing rat lung. Am J Physiol Lung Cell Mol Physiol 2000;279:600-607.

16 Grover TR, Parker TA, Abman SH: Vascular endothelial growth factor improves pulmonary vascular reactivity and structure in an experimental model of chronic pulmonary hypertension in fetal sheep. Chest 2005;128:614S. 


\section{Cellular Physiology Cell Physiol Biochem 2016;39:385-394 \begin{tabular}{l|l|l}
\hline DOI: 10.1159/000445632 & $\begin{array}{l}\text { C } 2016 \text { The Author(s). Published by S. Karger AG, Basel } \\
\text { www.karger.com/cpb }\end{array}$
\end{tabular}}

Liu et al.: VEGF Signaling in Esophageal Atresia Lungs

17 Lassus P, Turanlahti M, Heikkila P, Andersson LC, Nupponen I, Sarnesto A, Andersson S: Pulmonary vascular endothelial growth factor and flt-1 in fetuses, in acute and chronic lung disease, and in persistent pulmonary hypertension of the newborn. Am J Respir Crit Care Med 2001;164:1981-1987.

18 Xiaomei L, Aras-Lopez R, Martinez L, Tovar JA: Lung hypoplasia in rats with esophageal atresia and tracheo-esophageal fistula. Pediatr Res 2012;71:235-240.

19 Towbin H, Staehelin T, Gordon J: Electrophoretic transfer of proteins from polyacrylamide gels to nitrocellulose sheets: Procedure and some applications. Proc Natl Acad Sci USA 1979;76:4350-4354.

20 Kovesi T: Long-term respiratory complications of congenital esophageal atresia with or without tracheoesophageal fistula: An update. Dis Esophagus 2013;26:413-416.

21 Cartabuke RH, Lopez R, Thota PN: Long-term esophageal and respiratory outcomes in children with esophageal atresia and tracheoesophageal fistula. Acta Paediatr Taiwan. 2002;43:348-350.

22 Oliveira GP, Silva JD, Marques PS, Gonçalves-de-Albuquerque CF, Santos HL, Vascocellos AP, Takiya CM, Morales MM, Pelosi P, Mócsai A, de Castro-Faria-Neto HC, Rocco PRM: The effects of dasatinib in experimental acute respiratory distress syndrome depend on dose and etiology. Cell Physiol Biochem 2015;36:1644-1658.

23 Chen CY, Tsao PN, Chou HC, Chen SJ, Tsou KI: Esophageal atresia associated with tracheal stenosis and right lung agenesis: Report of one case. Acta Paediatr Taiwan 2002; 43:348-350.

24 Goyal A, Jones MO, Couriel JM, Losty PD: Oesophageal atresia and tracheo esophageal fistula. Arch Dis Child Fetal Neonatal Ed 2006;91:381-384.

25 Fragoso AC, Aras-Lopez R Fau - Martinez L, Martinez L Fau - Estevao-Costa J, Estevao-Costa J Fau - Tovar JA, Tovar JA: Abnormal control of lung branching in experimental esophageal atresia. Pediatr Surg Int 2013;29:171-177.

26 Fragoso AC, Martinez L, Estevao-Costa J, Tovar JA: Abnormal sonic hedgehog signaling in the lung of rats with esophageal atresia induced by adriamycin. Pediatr Res 2014;76:355-362.

27 Burri PH: Structural aspects of postnatal lung development - alveolar formation and growth. Biol Neonate 2006;89:313-322.

28 Warburton D, Schwarz M, Tefft D, Flores-Delgado G, Anderson KD, Cardoso WV: The molecular basis of lung morphogenesis. Mech Dev 2000;92:55-81.

29 Cardoso WV: Molecular regulation of lung development. Annu Rev Physiol 2001;63:471-494.

30 Cardoso WV, Lu J: Regulation of early lung morphogenesis: Questions, facts and controversies. Development 2006; 133:1611-1624.

31 Ware LB, Matthay MA: Keratinocyte and hepatocyte growth factors in the lung: Roles in lung development, inflammation, and repair. Am J Physiol Lung Cell Mol Physiol 2002;282:L924-940.

32 Ferrara N, Gerber HP, LeCouter J: The biology of vegf and its receptors. Nat Med 2003;9:669-676.

33 Shinkai M, Shinkai T, Montedonico S, Puri P: Effect of vegf on the branching morphogenesis of normal and nitrofen-induced hypoplastic fetal rat lung explants. J Pediatr Surg 2006;41:781-786.

34 Compernolle V, Brusselmans K, Acker T, Hoet P, Tjwa M, Beck H, Plaisance S, Dor Y, Keshet E, Lupu F, Nemery B, Dewerchin M, Van Veldhoven P, Plate K, Moons L, Collen D, Carmeliet P: Loss of hif-2alpha and inhibition of vegf impair fetal lung maturation, whereas treatment with vegf prevents fatal respiratory distress in premature mice. Nat Med 2002;8:702-710.

35 Fong GH, Rossant J, Gertsenstein M, Breitman ML: Role of the flt-1 receptor tyrosine kinase in regulating the assembly of vascular endothelium. Nature 1995;376:66-70.

36 Shalaby F, Rossant J, Yamaguchi TP, Gertsenstein M, Wu XF, Breitman ML, Schuh AC: Failure of blood-island formation and vasculogenesis in flk-1-deficient mice. Nature 1995;376:62-66.

37 Brown KR, England KM, Goss KL, Snyder JM, Acarregui MJ: Vegf induces airway epithelial cell proliferation in human fetal lung in vitro. Am J Physiol Lung Cell Mol Physiol 2001;281:1001-1010.

38 Raoul W, Chailley-Heu B, Barlier-Mur AM, Delacourt C, Maitre B, Bourbon JR: Effects of vascular endothelial growth factor on isolated fetal alveolar type II cells. Am J Physiol Lung Cell Mol Physiol 2004;286:12931301.

39 McGillick EV, Orgeig S, Morrison JL: Structural and molecular regulation of lung maturation by intratracheal vascular endothelial growth factor administration in the normally grown and placentally restricted fetus, J Physiol 2016;594:1399-1420.

40 Shinkai M, Shinkai T, Montedonico S, Puri P: Effect of vegf on the branching morphogenesis of normal and nitrofen-induced hypoplastic fetal rat lung explants. J Pediatr Surg 2006;41:781-786. 